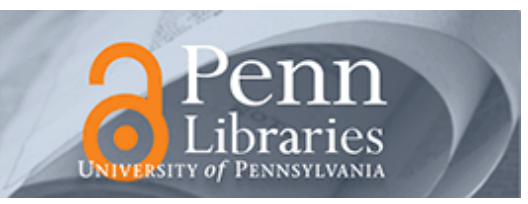

University of Pennsylvania

ScholarlyCommons

October 2003

\title{
Conducting Empirical Research on Informed Consent: Challenges and Questions
}

\author{
Greg A. Sachs \\ Gavin W. Hougham \\ Jeremy Sugarman \\ Patricia Agre \\ University of Pennsylvania \\ Marion E. Broome \\ University of Alabama
}

See next page for additional authors

Follow this and additional works at: https://repository.upenn.edu/bioethics_papers

\section{Recommended Citation}

Sachs, G. A., Hougham, G. W., Sugarman, J., Agre, P., Broome, M. E., Geller, G., Kass, N., Kodish, E., Mintz, J., Roberts, L. W., Sankar, P., Siminoff, L. E., Sorenson, J., \& Weiss, A. (2003). Conducting Empirical Research on Informed Consent: Challenges and Questions. Retrieved from https://repository.upenn.edu/ bioethics_papers/27

\footnotetext{
(C) The Hastings Center. Reprinted by permission. This article originally appeared in the IRB: Ethics and Human Research Special Supplement, Volume 25, Issue 3, October 2003, pages S4-S10.

Publisher URL: http://www.thehastingscenter.org/publications/hcr/hcr.asp

This paper is posted at ScholarlyCommons. https://repository.upenn.edu/bioethics_papers/27

For more information, please contact repository@pobox.upenn.edu.
} 


\section{Conducting Empirical Research on Informed Consent: Challenges and Questions}

\section{Comments}

(C) The Hastings Center. Reprinted by permission. This article originally appeared in the IRB: Ethics and Human Research Special Supplement, Volume 25, Issue 3, October 2003, pages S4-S10.

Publisher URL: http://www.thehastingscenter.org/publications/hcr/hcr.asp

\section{Author(s)}

Greg A. Sachs, Gavin W. Hougham, Jeremy Sugarman, Patricia Agre, Marion E. Broome, Gail Geller, Nancy Kass, Eric Kodish, Jim Mintz, Laura W. Roberts, Pamela Sankar, Laura E. Siminoff, James Sorenson, and Anita Weiss 


\section{Conducting Empirical Research on Informed Consent: Challenges and Questions}

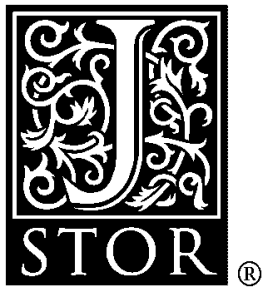

Greg A. Sachs; Gavin W. Hougham; Jeremy Sugarman; Patricia Agre; Marion E. Broome; Gail Geller; Nancy Kass; Eric Kodish; Jim Mintz; Laura W. Roberts; Pamela Sankar; Laura A. Siminoff; James Sorenson; Anita Weiss

IRB: Ethics and Human Research, Vol. 25, No. 5, Supplement. (Sep. - Oct., 2003), pp. S4-S10.

Stable URL:

http://links.jstor.org/sici?sici=0193-7758\%28200309\%2F10\%2925\%3A5\%3CS4\%3ACEROIC\%3E2.0.CO\%3B2-W

IRB: Ethics and Human Research is currently published by The Hastings Center.

Your use of the JSTOR archive indicates your acceptance of JSTOR's Terms and Conditions of Use, available at http://www.jstor.org/about/terms.html. JSTOR's Terms and Conditions of Use provides, in part, that unless you have obtained prior permission, you may not download an entire issue of a journal or multiple copies of articles, and you may use content in the JSTOR archive only for your personal, non-commercial use.

Please contact the publisher regarding any further use of this work. Publisher contact information may be obtained at http://www.jstor.org/journals/hastings.html.

Each copy of any part of a JSTOR transmission must contain the same copyright notice that appears on the screen or printed page of such transmission.

JSTOR is an independent not-for-profit organization dedicated to and preserving a digital archive of scholarly journals. For more information regarding JSTOR, please contact support@jstor.org. 


\section{Conducting Empirical Research on Informed Consent:}

Challenges and Questions

by Greg A. Sachs, Gavin W. Hougham, Jeremy Sugarman, Patricia Agre, Marion E. Broome, Gail Geller, Nancy Kass, Eric Kodish, Jim Mintz, laura W. Roberts, Pamela Sankar, laura A. Siminoff, James SORENSON, AND ANITA WeISS

倿 he informed consent projects (ICPs) we describe here were designed to produce (1) new and improved methods for the informed consent process, (2) methods for confronting the challenges of obtaining consent for special or vulnerable populations, and ( 3 ) data to help inform and guide public policy development (Table 1). From the outset, the project investigators identified a number of conceptual and practical concerns and challenges in conducting empirical research on informed consent. These concerns and challenges were shared by all the investigators, despite the significant variability in the research methods used and the populations studied. Experienced researchers will recognize that some of these concerns and challenges are common to many kinds of research involving human subjects. Some, however, are unique to research on informed consent. We describe these matters for the purpose of fostering ongoing dialogue about the challenges researchers face in studying the informed consent process.

Greg A. Sachs, Gavin W. Hougham, Jeremy Sugarman, Particia Agre, Marion E. Broome, Gail Geller, Nancy Kass, Eric Kodish, Jim Mintz, Laura W. Roberts, Pamela Sankar, Laura A. Siminoff, James Sorenson, and Anita Weiss, "Conducting Empirical Research on Informed Consent:

Challenges and Questions," IRB: Ethics \& Human Research Supplement 25 No. 5 (2003): S4-S1O.

\section{Common Research Challenges}

Study Design Issues. As is the case with other kinds of research, investigators who study the informed consent process face basic study design issues. Some of the ICPs examined the disclosure or informing part of the informed consent process; others focused on autonomy and decisionmaking for research participation; and some examined the process in its entirety. The range of study designs included (1) studying factors influencing decisionmaking preferences of potential research subjects (sometimes using hypothetical research protocols), (2) testing innovative informed consent procedures, (3) observing the informed consent process of research being conducted by other investigators, and (4) experimenting with various informed consent methods for active clinical trials being conducted by other investigators.

As with other research, trade-offs are involved in selecting one design or another. Examining responses of potential research subjects to hypothetical protocols, for example, allows researchers the greatest control over study conditions. On the other hand, responses to hypothetical vignettes may not accurately reflect how potential subjects make decisions in real consent encounters. Surveys or interviews with partici- pants in actual research moves a step closer to informed consent encounters as they occur, but are subject to recall, social desirability, and other forms of reporting bias.

Some of the ICPs either directly observed informed consent processes of other researchers, or audiotaped or videotaped these consent encounters. These approaches have the advantage of directly studying the events a potential research subject encounters when asked to give informed consent. On the other hand, such methods might have the unintended consequence of altering the behavior of the observed participants (i.e., "Hawthorne effects"). Furthermore, to the extent that any of the research designs concentrated on informed consent as a single encounter, they risked missing the import of viewing informed consent as a process consisting of multiple conversations and interactions.

Approaches that rely on access to other investigators' subjects raise additional concerns because the informed consent researcher is asking an investigator and his or her staff to be subjects of an informed consent study. These concerns provoked extensive discussion among the ICP investigators and will be revisited separately below.

Another design issue not unique to the ICPs relates to the use of qualitative compared with quantitative 
research methods. While most physician-investigators involved in clinical or health services research commonly use quantitative measures (e.g., blood pressure response to new agents), social scientists often use qualitative methods in the medical research context (e.g., analyzing subjects' responses to open-ended questions). ${ }^{2}$ The pros and cons of qualitative and quantitative methods are well described elsewhere. ${ }^{3}$ Many of the ICP investigators believe that a combination of the two approaches is most appropriate in studying the informed consent process. ${ }^{4}$

\section{Institutional Review Board} Approval. Investigators of all kinds often view institutional review board (IRB) approval of their protocols as an obstacle to be overcome. One might presume that the ICP investigators, some of whom are recognized experts on informed consent, ought to have knowledge and experience that would allow them to readily negotiate the IRB review process. To the contrary, many of the ICP investigators experienced more difficulty in obtaining IRB approval for the informed consent studies than they did for much higher risk research, such as cancer chemotherapy trials. We believe some of these IRB delays were attributable to the use of research methods that are routine in the social sciences but that are unfamiliar to biomedical-oriented IRBs.

Some ICP investigators involved in multicenter studies experienced significant variability in how IRBs at different institutions handled the same protocol, a common issue for all researchers conducting multicenter clinical trials. ${ }^{5}$ For example, IRBs at three different institutions that reviewed one of the informed consent projects made suggestions for consent procedures that spanned the spectrum from simple oral consent to an extensive, multipart written consent form.

For the project that involved randomly assigning subjects to one of four different consent methods (standard form, booklet form, video, and computer-assisted instruction) the relevant IRB initially insisted that investigators approach prospective participants only after these individuals had signed a consent form for the primary clinical trial. Obtaining informed consent under this scenario would have confounded the informed consent study because study subjects would already have completed the standard informed consent process and enrolled in the primary study. After much discussion, the IRB approved the informed consent study as originally designed. These and other similar examples demonstrate how novel and unfamiliar empirical research on informed consent might appear to some IRBs, despite decades of ethical, legal, and regulatory analysis of informed consent.

Responding to Rapid Change in Clinical Care. Some of the ICP investigators confronted challenges to their study plans due to unexpected and significant changes in the clinical arena. Investigators with experience conducting clinical trials may have had studies altered or stopped due to new findings presented at national scientific meetings or published in medical and scientific journals. A striking example of this kind of change among the ICPs was a study that planned to examine informed consent in early phase research studies enrolling patients with cancer or HIV. With the tremendous success of highly active antiretroviral therapy for HIV infection, the number of people eligible for phase I and other early stage HIV drug research plummeted. As a consequence, informed consent researchers had to make major changes in their plans to study HIV patients.

Another area in which the changing clinical scene affected at least the rate of subject accrual involved two ICPs that examined the consent process of phase III studies of drugs for Alzheimer disease. Enrollment rates for these studies slowed with the availability of three approved medications for the disease. Many patients and family members appeared less eager to enroll in studies, especially placebo-controlled trials, once even modestly effective drugs became available.

\section{Special Challenges for Empirical Research on Informed Consent}

- Researchers as Gatekeepers to Subjects. Researchers conducting studies on informed consent face a number of challenges surrounding the thorny issues of recruiting, enrolling, and studying other researchers, as well as the researchers' subjects. Difficulty in recruiting subjects is a common problem in all kinds of human subjects research. ${ }^{6}$ Investigators often need the cooperation or "buy-in" of clinicians caring for patients who are potential subjects of trials. For those of us studying informed consent, there were added layers of complexity. We had to gain cooperation of clinical researchers, clinical providers, and patient-subjects-all who were in some ways "subjects" of the ICP investigators. On the simplest level, this meant that clinical researchers functioned as gatekeepers to our access to the informed consent process. From the standpoint of those interested in studying informed consent, the more people who can say "no" along the way, the greater the difficulty in conducting adequate numbers of studies and recruiting adequate numbers of subjects.

The ICP investigators were also faced with the problem of selection biases, some operating potentially on more than one level. None of the ICP investigators attempted to study a randomly drawn sample of research projects. The methods used to select the clinical investigators to approach for our studies introduced a number of potential biases. Investigators who were willing to allow us to examine, or even modify, 
Table 1. NIH-funded Investigators and Projects

\begin{tabular}{|c|c|c|c|c|}
\hline Investigator & \multirow{2}{*}{$\begin{array}{l}\text { Co-Investigators } \\
\text { Dougherty, Holland, Kurtz, } \\
\text { Offit, Rapkin, Wilson }\end{array}$} & Institutional Affiliation & \multicolumn{2}{|c|}{ Title of Project } \\
\hline Agre, Patricia & & $\begin{array}{l}\text { Memorial Sloan-Kettering } \\
\text { Cancer Center }\end{array}$ & \multicolumn{2}{|c|}{$\begin{array}{l}\text { A Comparison of Methods to Provide } \\
\text { Informed Consent Information }\end{array}$} \\
\hline Broome, Marion & $\begin{array}{l}\text { Liaschenko, Nelson, } \\
\text { Pletsch, Richards, Snethen, } \\
\text { Stevens, Underwood }\end{array}$ & $\begin{array}{l}\text { University of Alabama, } \\
\text { Birmingham }\end{array}$ & \multicolumn{2}{|c|}{$\begin{array}{l}\text { III Children and Their Parents: Experience } \\
\text { with Research }\end{array}$} \\
\hline Campbell, Frances & Boccia, Goldman & $\begin{array}{l}\text { University of North } \\
\text { Carolina at Chapel Hill }\end{array}$ & \multicolumn{2}{|c|}{$\begin{array}{l}\text { Improving the Consent Process for Low-Literacy } \\
\text { Parents }\end{array}$} \\
\hline Geller, Gail & $\begin{array}{l}\text { Bernhardt, Tambor, } \\
\text { Fraser, Wissow }\end{array}$ & $\begin{array}{l}\text { Johns Hopkins University } \\
\text { (Medicine) }\end{array}$ & \multicolumn{2}{|c|}{$\begin{array}{l}\text { Minors at Risk of Future Disease: Their Role in } \\
\text { Research }\end{array}$} \\
\hline Gribble, James & $\begin{array}{l}\text { Bostrum, Fischhoff, } \\
\text { Helzlsouer, Miller }\end{array}$ & Research Triangle Institute & \multicolumn{2}{|c|}{$\begin{array}{l}\text { Evaluating Informed Consent in BRCA } 1 / 2 \\
\text { Screening }\end{array}$} \\
\hline Kass, Nancy & $\begin{array}{l}\text { Sugarman, Fogarty, Taylor } \\
\text { Goodman, Carducci, } \\
\text { Hurwitz }\end{array}$ & $\begin{array}{l}\text { Johns Hopkins University } \\
\text { (Public Health), Duke } \\
\text { University Medical Center }\end{array}$ & \multicolumn{2}{|c|}{$\begin{array}{l}\text { Improving Understanding in Early Phase Clinical } \\
\text { Research }\end{array}$} \\
\hline Kodish, Eric & $\begin{array}{l}\text { Siminoff, Drotar, Lange, } \\
\text { Noll, Angiolillo, Ruccione, } \\
\text { Pentz }\end{array}$ & $\begin{array}{l}\text { Rainbow Center for } \\
\text { Pediatric Ethics, Rainbow } \\
\text { Babies \& Children's Hospital }\end{array}$ & \multicolumn{2}{|c|}{$\begin{array}{l}\text { Informed Consent in the Children's Cancer } \\
\text { Group }\end{array}$} \\
\hline Lidz, Charles & Appelbaum, Grisso & $\begin{array}{l}\text { University of } \\
\text { Massachusetts, Worcester }\end{array}$ & \multicolumn{2}{|c|}{$\begin{array}{l}\text { Informed Consent and the Therapeutic } \\
\text { Misconception }\end{array}$} \\
\hline $\begin{array}{l}\text { their informed cc } \\
\text { may have been a } \\
\text { perhaps those mo } \\
\text { they were alread } \\
\text { with informed co } \\
\text { sible that selectio } \\
\text { clinical researche } \\
\text { the trials made a } \\
\text { For example, on } \\
\text { met with resistan } \\
\text { protocols paid fo } \\
\text { companies due to } \\
\text { "ownership" of } \\
\text { data involved in } \\
\text { Similarly, clini } \\
\text { might have limite } \\
\text { jects or preselecte } \\
\text { their trials for pa } \\
\text { studies. Some res } \\
\text { altered their selec } \\
\text { order to recruit } n \\
\text { tent subjects beca } \\
\text { that subjects wor }\end{array}$ & $\begin{array}{l}\text { self-selected group, } \\
\text { ost confident that } \\
\text { y doing a good job } \\
\text { nsent. It is also pos- } \\
\text { n bias entered if a } \\
\text { relected or limited } \\
\text { vailable for scrutiny. } \\
\text { ICP investigator } \\
\text { ce to inclusion of } \\
\text { r by pharmaceutical } \\
\text { concerns about } \\
\text { participants and } \\
\text { these trials. } \\
\text { cal researchers } \\
\text { ed our access to sub- } \\
\text { ed subjects from } \\
\text { rticipation in ICP } \\
\text { earchers might have } \\
\text { ction practices in } \\
\text { nore clearly compe- } \\
\text { ause they anticipated } \\
\text { ald be closely }\end{array}$ & $\begin{array}{l}\text { observed and perhaps subjec } \\
\text { formal testing of comprehens } \\
\text { Researchers might also have } \\
\text { our access to subjects due to } \\
\text { cerns about potential additio } \\
\text { dens or distress for their rese } \\
\text { subjects in an effort to avoid } \\
\text { higher refusal or attrition rat } \\
\text { their own studies. Conversely } \\
\text { ICP investigator had to decid } \\
\text { to respond to a research colle } \\
\text { who was seemingly overly co } \\
\text { tive in referring subjects for } t \\
\text { informed consent study. The } \\
\text { investigator was concerned th } \\
\text { individuals the colleague refe } \\
\text { would never have considered } \\
\text { ing to participate. Some ICP } \\
\text { gators thought it better to ha } \\
\text { own staff responsible for recr } \\
\text { to avoid these potential prob } \\
\text { We also recognized that cl } \\
\text { research staff and subjects m }\end{array}$ & $\begin{array}{l}\text { cted to } \\
\text { limited } \\
\text { con- } \\
\text { onal bur- } \\
\text { earch } \\
\text { d risking } \\
\text { tes in } \\
\text { ly, one } \\
\text { de how } \\
\text { league } \\
\text { oopera- } \\
\text { the } \\
\text { ICP } \\
\text { that the } \\
\text { erred } \\
\text { d declin- } \\
\text { investi- } \\
\text { ave their } \\
\text { ruitment } \\
\text { blems. } \\
\text { linical } \\
\text { ight }\end{array}$ & $\begin{array}{l}\text { alter their behavior during the con- } \\
\text { sent process simply because they } \\
\text { knew they were being observed. For } \\
\text { example, the clinical research staff } \\
\text { might improve their standard con- } \\
\text { sent process to the extent that poten- } \\
\text { tial differences between standard and } \\
\text { innovative consent methods would } \\
\text { be obscured. This could result in } \\
\text { false negative study conclusions- } \\
\text { deciding an intervention does not } \\
\text { improve the consent process and } \\
\text { thus abandoning it because of a ceil- } \\
\text { ing effect induced by the studies } \\
\text { themselves. An effect such as this is } \\
\text { troubling because the improvements } \\
\text { in the standard consent process on } \\
\text { the part of the clinical research staff } \\
\text { might not continue once observation } \\
\text { by ICP investigators ended. } \\
\text { One ICP investigator pointed out } \\
\text { that tensions between clinical } \\
\text { researchers and investigators study- }\end{array}$ \\
\hline
\end{tabular}




\begin{tabular}{|c|c|c|c|}
\hline Investigator & Co-Investigators & Institutional Affiliation & Title of Project \\
\hline $\begin{array}{l}\text { McCullough, } \\
\text { Laurence }\end{array}$ & Paterniti & Baylor College of Medicine & $\begin{array}{l}\text { Enhancing the Autonomy of Vulnerable Subjects of } \\
\text { Research }\end{array}$ \\
\hline McKay, Mary & & $\begin{array}{l}\text { University of Illinois, } \\
\text { Chicago }\end{array}$ & $\begin{array}{l}\text { Informed Consent in Urban AIDS and Mental Health } \\
\text { Research }\end{array}$ \\
\hline Merz, Jon & Sankar & University of Pennsylvania & Informed Consent to DNA Banking for Research \\
\hline Miller, Suzanne & Driscoll, Green & Fox Chase Cancer Center & $\begin{array}{l}\text { Facilitating Well-Informed Decisions for BRCA } \\
\text { Testing }\end{array}$ \\
\hline Mintz, Jim & Wirshing & UCLA & $\begin{array}{l}\text { Consenting to Psychiatric and Medical Treatment } \\
\text { Research }\end{array}$ \\
\hline Meuller, Mary-Rose & & $\begin{array}{l}\text { University of California, } \\
\text { San Diego }\end{array}$ & Dynamics of Informed Consent in AIDS Clinical Trials \\
\hline Roberts, Laura & Brody, Roberts, Warner & University of New Mexico & $\begin{array}{l}\text { Vulnerability and Informed Consent in Clinical } \\
\text { Research }\end{array}$ \\
\hline Sachs, Greg & $\begin{array}{l}\text { Hougham, Brauner, } \\
\text { Danner, Friesen, } \\
\text { Whitehouse, Patterson, } \\
\text { Ripich }\end{array}$ & $\begin{array}{l}\text { University of Chicago, } \\
\text { University of Kentucky, } \\
\text { Case Western Reserve } \\
\text { University }\end{array}$ & $\begin{array}{l}\text { Dementia Research: Informed, Proxy, and } \\
\text { Advance Consent }\end{array}$ \\
\hline Siminoff, Laura & Weiss & $\begin{array}{l}\text { Case Western Reserve } \\
\text { University }\end{array}$ & $\begin{array}{l}\text { Therapeutic Research Consent: } \\
\text { Empirical/Ethical Analysis }\end{array}$ \\
\hline Sorenson, James & $\begin{array}{l}\text { Jennings-Grant, Lakon, } \\
\text { Spinney }\end{array}$ & $\begin{array}{l}\text { University of North } \\
\text { Carolina at Chapel Hill }\end{array}$ & $\begin{array}{l}\text { An Experimental Study to Improve Risk/Benefit } \\
\text { Appraisal }\end{array}$ \\
\hline
\end{tabular}

ing informed consent could be traced to understandable concerns about self-interest and personal agendas. Clinical researchers presumably have an interest in demonstrating that "problems" with the consent process are either nonexistent, less serious than thought, or remediable; ethics researchers arguably have an agenda to find issues worthy of thought, debate, and remediation. The challenge to the ICP investigators was to remain objective in the face of widespread acceptance of the tenet that "the process is broken" and that various populations are "at risk" or "vulnerable," including those deemed to have decisional impairments.

Researchers as Subjects of Informed Consent Research. We also encountered a number of concerns related to the role of clinical researchers as subjects of the informed consent studies, rather than merely as gatekeepers to their patient-subjects. First, some of the ICP investigators reported that a number of clinical researchers were reluctant to be observed during informed consent processes, perhaps fearing being judged and critiqued, or of having negative actions taken against them, their research, or their institutions if serious shortcomings were found.

Second, though we promised confidentiality for subjects in the ICP studies, the clinical researchers were, in fact, at greater risk of having their confidentiality violated because they were more readily identifiable than typical research subjects. Many ICP investigators studied convenience samples of researchers at their own institutions. Depending on the size of the institution, the numbers of clinical researchers involved, and the nature of the clinical trials being studied, it is possible that the description of a clinical research protocol might make a researcher identifiable to knowledgeable readers, including funding agencies and research ethics monitors. Some ICP investigators informed the clinical researchers of this potential violation of confidentiality, even if they were not using a formal, written informed consent process for the researchers' participation. One ICP investigator urged that those studying informed consent routinely try to involve more than one institution in their work in order to provide greater anonymity to the clinical researchers under study.

Third, some clinical researchers were concerned that ICPs might 
lower enrollment rates in their clinical studies. For those ICPs that experimented with methods to improve the informed consent process, there was the possibility that better understanding of the potential risks or possible benefits of research participation would lead to lower enrollment rates.

We also recognized that an improved informed consent process might increase enrollment or subject retention, especially if the improved process resulted in a better match between a subject's expectations and his or her experience within the study. Some clinical researchers were concerned specifically that our methods might be either too intrusive or too burdensome (e.g., video or audio taping). They feared that overwhelmed subjects might decline participation in both the informed consent study and the clinical research. For example, some complex oncology protocols presented multiple consent forms to prospective subjects prior to an ICP investigator's introducing his or her own procedures or documents to empirically study the informed consent process.

Disrupting patient flow in clinics or in the process of counseling for genetic testing were two other concerns raised by some of the ICP investigators.

\section{Informed Consent to Study Informed Consent. Obtaining} informed consent to study informed consent was an interesting phenomenon encountered by the ICP investigators. Some of the issues discussed regarding our own informed consent processes related to the type of consent required for this kind of research (written consent or oral consent or consent requirements being waived), and how IRBs were dealing with these issues around the country.

As mentioned above, for those of us either observing other researchers or intervening in someone else's research, there were many questions about obtaining the informed con- sent of clinical investigators and their research staff. What exactly are the potential risks and benefits to researchers who permit other researchers access to their work? Certainly, there are risks related to potential violations of confidentiality, especially in cases where problems with the consent process are uncovered. Moreover, if the informed consent study involved comparing different procedures for obtaining informed consent, could the clinical research staff reliably implement the alternative methods without contamination? Could clinical research staff be kept blinded to informed consent study procedures and interim analyses?

An early concern raised by some ICP investigators was the complexity of our informed consent procedures, especially for those of us whose subjects were also enrolling in clinical trials. Some of us were trying to explain to patients newly diagnosed with cancer or some other serious illness that we wanted their permission to randomly assign them to different consent processes that would be embedded in their being randomly assigned to one treatment regimen or another.

Situations like this complicate the already challenging task of explaining the primary clinical trial. ${ }^{8}$ One ICP investigator described asking patient-subjects eligible for cancer trials about their willingness to be in her informed consent study, which involved interviewing the patients about what they understood concerning cancer trials just described to them by oncology staff. For this researcher, it was somewhat disconcerting to have patient-subjects pick up the consent form for the informed consent study, sign it without reading it, smile, and say, "I don't need to read this, I trust you." Did they do the same when asked to participate in the cancer trial, and if they did, should this worry us? This encounter highlights the importance of trust in the informed consent process, a factor potentially both more powerful and less well examined than aspects of disclosure and comprehension studied in so much of the empirical research on informed consent. ${ }^{9}$

When to Intervene? Some ICP investigators struggled with concerns about what they should do if they thought the clinical researchers they were observing were engaging in suboptimal, problematic, or potentially unethical practices during the informed consent process. ${ }^{10}$ Some ICP investigators said they would feel morally obliged to intervene in such cases. Others expressed concerns about acting as "ethics police" and potentially damaging their relationships with researchers who had allowed the observations to be made in the first place, perhaps even threatening their ability to conduct the informed consent studies altogether.

Several ICP investigators with extensive experience on their home IRBs suggested that although the content might be different, this issue does have a parallel in clinical trials. In clinical trials, thoughtful researchers disclose to subjects that a trial may be discontinued (or a particular subject's participation ended) for various predetermmined reasons, including uncovering new, clinically relevant information or because of results from other studies. For example, in a study to determine the prevalence of depression in nursing homes, investigators needed to decide how to handle the information when patients were found to be depressed on their screening exams and the depression had not been detected or treated by the patient's clinician. ${ }^{11}$

We wondered if informed consent researchers could develop in advance of going into the field a similar list of criteria and procedures for intervening. One ICP investigator suggested that ethics researchers ought to be held to a higher level of ethics accountability as leaders and poten- 
tial role models within our respective institutions. Anticipated difficulties and responses could be disclosed to the IRB and communicated to researchers and other subjects during the informed consent process. Even with this disclosure, some ICP investigators expressed concerns about trying to balance duties to different parties in the research enterprise, especially with respect to clinical investigators who are subjects of informed consent research.

Anticipating the Public Policy Implications. The final area for discussion is the importance of informed consent researchers giving careful and early consideration to the implications of their research findings, including how various stakeholders might use their findings. The scrutiny of research ethics is increasing steadily in the United States. ${ }^{12}$ Major medical centers have had their research operations suspended due to inadequate review of research or other ethical improprieties. To use language from a recent review, we are clearly moving toward an era of "strong protectionism" in human subjects research. ${ }^{13}$ However, the consequences of such a change will bring added costs, increased complexity, and possibly a halt to some kinds of research altogether. ${ }^{14}$ Ever increasing requirements on IRBs for ongoing review of research and other new regulations add to the work of those overseeing research. Findings of the ICPs that revealed deficiencies in an informed consent process could be used by interested parties to advocate for additional regulations, alterations in funding for some kinds of research, or other ends not intended by the ICP researchers.

One ICP investigator told of his difficulties in getting the results of an earlier study published. The paper reported some ethical concerns about research conducted in a specific setting. One reviewer at a prestigious journal referred to existing difficulties involved in conducting research in that setting, and contend- ed that the difficulties would be exacerbated by publication of the ethics report. The other manuscript reviewer expressed concerns about the potential impact of the paper on funding for research in that particular setting. On the other hand, how would various stakeholders and interest groups (policy, science, or advocacy) respond to a study that found "no" or "little" evidence of problems with the informed consent process? It is clear that research on informed consent is rife with important policy and political ramifications.

\section{Conclusion}

$\mathrm{VJ}^{\mathrm{e}}$ have discussed many of the Whallenges involved in conducting empirical research on informed consent. Some of these, such as the issues involved in relying on the cooperation of clinical researchers for access to the consent processes of their studies, and having those researchers as subjects of the research on informed consent, do not have simple solutions. Like much of clinical research, there likely will be an ongoing tension in informed consent research between goals and a balancing of benefits and burdens of the various strategies used to address these issues.

Despite these challenges and concerns, the ICP studies have produced interesting and important findings. Some of these hold the promise of final products, such as an assessment instrument or an innovation to the informed consent process, that can be applied in other settings and potentially enhance the informed consent process.

One observation from the studies is that regardless of the subject population or type of research, the informed consent process appears to start far earlier than the encounter at which the consent form is signed. The process tends to be incremental as information about the proposed research is framed, shared, and processed. By the time an official consent encounter takes place, subjects may already have made their decision about enrollment. Federal regulations that would bring greater scrutiny to the informed consent encounter itself may miss important social and even cultural dimensions about how subjects and researchers are brought together starting with initial, tentative, and often informal inquiries. Our research findings may generate new questions and challenges, even as we help answer existing questions about the informed consent process.

\section{Acknowledgment}

All authors have received direct or indirect support from the National Institutes of Health. We thank the agencies and program officers at $\mathrm{NIH}$ for their support of empirical research on informed consent. The views expressed in this article are those of the authors and do not necessarily reflect the views of funding agencies. The authors are grateful for early discussions of the themes developed here with Jon F. Merz and other participants at the annual meetings of the grantees.

\section{References}

1. Neaton JD. Impact of the Hawthorne effect in a longitudinal clinical study: The case of anesthesia. Controlled Clinical Trials 2000;21(4): 381-382; Wickstrom G, Bendix T. The "Hawthorne effect" - what did the original Hawthorne studies actually show? Scandinavian Journal of Work Environment \& Health 2000;26(4): 363-367; De Amici D, Klersy C, Ramajoli F, Brustia L, Politi P. Impact of the Hawthorne effect in a longitudinal clinical study: The case of anesthesia. Controlled Clinical Trials 2000;21(2): 103114.

2. Morgan DL. Qualitative content analysis: A guide to paths not taken. Qualitative Health Research 1993;3(1): 112-121.

3. Inui TS. The virtue of qualitative and quantitative research. Annals of Internal Medicine 1996;1 25(9): 770-771; Sofaer S. Qualitative methods: What are they and why use them? Health Services Research 1999;34(5 Pt 2): 1101-1118; Shortell SM. The emergence of qualitative methods in health services research. Health Services Research 1999;34(5 Pt 2): 1083-1090.

4. Alford RR. The theoretical power of multiple paradigms. In: The Craft of Inquiry: Theories, Methods, Evidence. New York: Oxford University Press, 1998, p. 103-120; 
Morgan DL. Practical strategies for combining qualitative and quantitative methods: Applications to health research. Qualitative Health Research 1998;8(3): 362-376; Sugarman J, Sulmasy DP, eds. Methods in Medical Ethics. Washington, DC: Georgetown University Press, 2001.

5. Lavori PW, Sugarman J, Hays MT, Feussner JR. Improving informed consent in clinical trials: A duty to experiment. Controlled Clinical Trials 1999;20(2): 187 193; Lynn J, Johnson J, Levine RJ. The ethical conduct of health services research: A case study of 55 institutions' applications to the SUPPORT project. Clinical Research 1994;42(1): 3-10.

6. Cosgrove N, Borhani NO, Bailey G et al. Mass mailing and staff experience in a total recruitment program for a clinical trial: The SHEP experience (Systolic Hypertension in the Elderly Program Cooperative Research Group). Controlled Clinical Trials 1999;20(2): 133-148; Crigger B-J. Recruiting subjects for clinical trials: Strategies and perils. Hastings Center Report 2000;30(4): 48.

7. Lied TR, Kazandjian VA. A Hawthorne strategy: Implications for performance measurement and improvement. Clinical

Performance Quality Health Care 1998;6(4): 201-204.

8. JAMA Patient Page Editor. Participating in medical research studies. JAMA 2001;285(5): 686 .

9. Kass NE, Sugarman J, Faden R, Schoch-Spana M. Trust: The fragile foundation of contemporary biomedical research. Hastings Center Report 1996;26(5): 25-9.

10. Wenger NS, Korenman SG, Berk R, Liu $\mathrm{H}$. Punishment for unethical behavior in the conduct of research. Academic Medicine 1998;73(11): 1187-1194; Wenger NS, Korenman SG, Berk R, Liu H. Reporting unethical research behavior. Evaluation Reveiw 1999;23(5): 553-570; Horner JS. Retreat from Nuremberg: Can we prevent unethical medical research? Public Health
1999;113(5): 205-210.

11. Coyne JC, Klinkman MS, Gallo SM, Schwenk TL. Short-term outcomes of detected and undetected depressed primary care patients and depressed psychiatric patients. General Hospital Psychiatry 1997;19(5): 333343; Rost K, Zhang M, Fortney J, Smith J, Coyne J, Smith GR. Persistently poor outcomes of undetected major depression in primary care. General Hospital Psychiatry 1998;20(1): 12-20.

12. Amdur RJ. Improving the protection of human research subjects. Academic Medicine 2000;75(7): 718-720.

13. Moreno JD. Goodbye to all that: The end of moderate protectionism in human subjects research. Hastings Center Report 2001;31(3): 9-17.

14. Michels R. Are research ethics bad for our mental health? JAMA 1999;340(18):

$1427-1434$. 